University of Nebraska - Lincoln

DigitalCommons@University of Nebraska - Lincoln

6-1-1989

\title{
Simultaneous Correlation of Excess Gibbs Energy and Enthalpy of Mixing by the UNIQUAC Equation
}

\author{
Yaşar Demirel \\ University of Çukurova, ydemirel2@unl.edu \\ Hatice Gecegörmez \\ University of Çukurova
}

Follow this and additional works at: https://digitalcommons.unl.edu/chemenganalytical

Part of the Chemical Engineering Commons

Demirel, Yaşar and Gecegörmez, Hatice, "Simultaneous Correlation of Excess Gibbs Energy and Enthalpy of Mixing by the UNIQUAC Equation" (1989). Papers in Analytical Chemistry. 3.

https://digitalcommons.unl.edu/chemenganalytical/3

This Article is brought to you for free and open access by the Chemical and Biomolecular Engineering Research and Publications at DigitalCommons@University of Nebraska - Lincoln. It has been accepted for inclusion in Papers in Analytical Chemistry by an authorized administrator of DigitalCommons@University of Nebraska - Lincoln. 


\title{
Simultaneous Correlation of Excess Gibbs Energy and Enthalpy of Mixing by the UNIQUAC Equation
}

YASAR DEMIREL and HATICE GECEGÖRMEZ

\author{
Faculty of Art and Sciences, University of Çukurova, Adana Turkey
}

\begin{abstract}
Using data for excess Gibbs energy, $g^{t}$, and enthalpy of mixing. $h^{t}$, temperature dependent parameters of the UNIQUAC equalion have been estimated for iwenty four systems of binary mixtures. Fifteen of them include data lior $g^{\prime}$ and $h^{\prime}$ at more than one different isotherm. These parameters are later tested in predicting the $g^{k}$ and $h^{t}$ data simultaneously and representing the effect of temperature on such data. The UNIQUAC equation with temperature dependent parameters represents larger values of maximum heat of nixing than does the UNIQUAC equation with the parameters independent of temperature.
\end{abstract}

\begin{abstract}
Nous alwons calculé à partir de donnćes obtenues pour l'inergie d'excès de Gibbs, $g^{E}$. et l'enthalpie de mélange. $h^{t}$. dès paramères dépendants de la température de l’équation UNIQUAC pour vingt-quatre systèmes de mélanges binaires. Quinze d'entre cux comprennent des donnćes pour $\xi^{t}$ et $h^{*}$ à plus d'un isotherme. Ces paramètres sont vérilićs par la suilc par la prédiction des donnćes de $g^{t}$ er $h^{t}$ simultanénent el par la représentation de l'effet de la tenpéralure sur ces donnécs. L’équation UNIQUAC dont les paramètres sont dépendants de la température fournit des valeurs plus grandes de la chaleur maximale du nélange que l'équalion UNIQUAC dont les paramètres sont indépendants de la tempéralure.
\end{abstract}

Keywords: excess Gibbs energy mixing enthalpy. UNIQUAC parameters. temperature dependent parameters.

$\mathbf{S}$ ince it was proposed by Abrams and Prausnitz (1975), the LiNIQUAC equation has been used successfully in 17uid phase equilibria predictions (Anderson and Prausnitz. 1978: Demirel, 1982). It is applicable to both vapour-liquid and liquid-liquid equilibria and has only two adjustable energy parameters. When the necessary care is exercised in reducing the binary data to estimate the parameters. the UNIQUAC equation provides a reliable basis for prediction of multicomponent fluid phase equilibria (Fredenslund et al., 1979; Demirel and McDermott, 1984). The UNIQUAC equation contains pure component structural parameters $r$ and $q$ Anderson and Prausnitz (1978) modified the UNIQUAC equation slightly and introduced new values of surface parameters, $q$ ' for alcohols and water to be used in the residual part of the equation.

\section{Heat of Mixing}

The rate of change of excess Gibbs free energy, $g^{E}$, and hence activity coefficient $\gamma_{i}$ with temperature is proportional to heat of mixing $h^{E}$, and given by the Gibbs-Helmoltz equation.

$$
\frac{h^{E}}{T^{2}}=-\left[\frac{\partial\left(g^{E} / T\right)}{\partial_{T}}\right]_{\rho, x} \ldots \ldots \ldots \ldots \ldots \ldots
$$

If $h^{E}$ at any composition is positive, then the value of $\gamma_{i}$ decreases with increase in temperanre. But if $h^{E}$ is negative then $\gamma_{i}$ increases with increasing temperature.

The Wilson equation and the NRTL equation are not capable of correlating both $g^{E}$ and $h^{E}$ data for a system where the value of heat of mixing is greater than a certain maximum value of $h^{E}$ at any given temperature (Murthy and Zudkevitch, 1979; Wilkinson, 1979). The limitations on the value of $h^{E}$ can be eliminated by treating the energy parameters of such equations as a function of temperature. For systems with strong hydrogen bonding, such as those containing alcohols, the heat of mixing can not be represented by the Wilson parameters with linear dependence of temperuture (Novak et al., 1974). A simultaneous fit of $g$ and $h^{E}$ data is successfully represented by the Wilson equation whose energy parameter differences are assumed to be a quadratic function of temperature (Murthy and Zudkevitch. 1979).

Renon (1971) and Nagata et al. (1973) assumed that the NRTL parameters change with temperature in a linear form. It has been shown by Nagata et al. (1976) that by using the temperature dependent parameters, the NRTL equation is capable of representing both vapour-liquid equilibria (VLE) and heat of mixing data with a single set of parameters, for the methyl acetate-benzene and methyl acetate-cyclohexane systems. This was achieved by fitting the parameters to both types of data simultaneously. Similar results were also obtained for the systems containing alcohols (Nagata et al.. 1972).

In the UNIQUAC equation, for each binary combination in a multicomponent mixture, there are two adjustable parameters $\tau_{21}$ and $\tau_{12}$. These are given in terms of characteristic energies $\Delta u_{21}$ and $\Delta u_{12}$ by

$$
\begin{aligned}
& \tau_{21}=\exp \left(-\Delta u_{21} / R T\right)=\exp \left(-a_{21} / T\right) \ldots \ldots \\
& \tau_{12}=\exp \left(-\Delta u_{12} / R T\right)=\exp \left(-a_{12} / T\right) \ldots \ldots
\end{aligned}
$$

Equations (2) and (3) give the primary effect of temperarure on $\tau_{21}$ and $\tau_{12}$. When the parameters $a_{21}$ and $a_{12}$ are used. enthalpy of mixing by the UNIQUAC equation is given as

$$
h^{E}=R\left(\frac{q_{1}^{\prime} x_{1} \theta_{2}^{\prime} \tau_{21} a_{21}}{\theta_{1}^{\prime}+\theta_{2}^{\prime} \tau_{21}}+\frac{q_{2}^{\prime} x_{2} \theta_{1}^{\prime} \tau_{12} a_{12}}{\theta_{2}^{\prime}+\theta_{1} \tau_{12}}\right)
$$

where

$$
\theta_{i}^{\prime}=q_{i}^{\prime} x_{i} /\left(\Sigma q_{i}^{\prime} x_{i}\right)
$$

If the first derivatives of $h^{E}$ with respect to the parameters $a_{21}$ and $a_{12}$ are obtained and set equal to zero, the new 
values of characteristic energies that give the maximum value of $h$ may be evaluated. For an equimolar mixture these are

$$
\frac{\tau_{21}}{\left(a_{21} / T-1\right)}=\frac{q_{1}^{\prime}}{q_{2}^{\prime}} \text { and } \frac{\tau_{12}}{\left(a_{12} / T-1\right)}=\frac{q_{2}^{\prime}}{q_{1}^{\prime}} \ldots
$$

Substituting Equation (5) into Equation (4) gives the maximum heat of mixing, $h^{\prime}$

$$
h^{\prime}=R T\left[q_{1}^{\prime} x_{1}\left(a_{21} / T-1\right)+q_{2}^{\prime} x_{2}\left(a_{12} / T-1\right)\right] \ldots
$$

Equation (6) shows that the maximum value of heat of mixing that can be predicted by the UNIQUAC equation is determined by the ratio of the surface parameters of the two components.

For the system methyl acetate-ethanol the value of $a_{21}$ and $a_{12}$ obtained from Equation (5), at $x_{1}=x_{2}=0.5$ and $T=45^{\circ} \mathrm{C}$ are $355.27 \mathrm{~K}$ and $502.35 \mathrm{~K}$ respectively. The value of $h^{\prime}$ that can be predicted by the UNIQUAC equation is equal to $1101.5 \mathrm{~J} / \mathrm{mol}$, while the experimental value of $h^{\prime}$ is about $1552.8 \mathrm{~J} / \mathrm{mol}$. This means that, for this system, the UNIQUAC equation, with the parameters independent of temperature, may not be capable of predicting enthalpy of mixing.

Characteristic energies $\Delta u_{21}$ and $\Delta u_{12}$ are often weakly dependent on temperature. Abrams and Prausnitz (1975) state that when both vapour-liquid and liquid-liquid equilibrium data are used to obtain UNIQUAC parameters, they appear to be smooth functions of temperature. However this is not the case for mixtures containing hydrogen bonding, such as water and alcohols (Anderson and Prausniz, 1978); Murthy and Zudkevitch, 1979). It is also known that in $\gamma_{i}$ varies with $1 / T$ (Reid et al., 1979). Therefore in this study, the effect of temperature on the characteristic energies is expressed as

$$
a_{i j}=\alpha_{i j}+\beta_{i j} / T \ldots \ldots \ldots \ldots \ldots \ldots \ldots
$$

which is also used by Anderson and Prausnitz (1978). With the UNIQUAC parameters given in Equation (7), the enthalpy of mixing becomes

$$
\begin{aligned}
h^{E} & =R\left[\frac{q_{1}^{\prime} x_{1} \theta_{2}^{\prime} \tau_{21}\left(\alpha_{21}+2 \beta_{21} / T\right)}{\theta_{1}^{\prime}+\theta_{2}^{\prime} \tau_{21}}\right. \\
& \left.+\frac{q_{2}^{\prime} x_{2} \theta_{1}^{\prime} \tau_{12}\left(\alpha_{12}+2 \beta_{12} / T\right)}{\theta_{2}^{\prime}+\theta_{1}^{\prime} \tau_{12}}\right] \ldots
\end{aligned}
$$

The maximum value of $h^{\prime}$ obtained from Equation (8), using the procedure explained above, is

$$
\begin{aligned}
h^{\prime} & =R T\left\{q_{1}^{\prime} x_{1}\left[\left(\alpha_{21}+2 \beta_{21} / T\right) / T-1\right]\right. \\
& \left.+q_{2}^{\prime} x_{2}\left[\left(\alpha_{12}+2 \beta_{12} / T\right) / T-1\right]\right] \ldots \ldots \ldots
\end{aligned}
$$

Positive values of $\beta_{21}$ and $\beta_{12}$ increase the values of parameters $a_{21}$ and $a_{12}$, thus Equation (9) represents larger values of $h^{\prime}$ than that of Equation (6).

\section{Estimation of Parameters}

In estimating the temperature dependent parameters, data for $g^{E}$ and $h^{E}$ were used simultaneously. The following objective function, which was also used by Nagata and Yamada (1973), was minimized.

$$
\begin{aligned}
F & =\frac{1}{N}\left\{\sum^{N} \frac{\sum^{n}\left[100\left(g_{\exp }^{E}-g_{\text {calc }}^{E}\right) / g_{\text {exp }}^{E}\right]^{2}}{n}\right\} \\
& +\frac{1}{M}\left\{\sum^{M} \frac{\sum^{m}\left[100\left(h_{\text {exp }}^{E}-h_{\text {calc }}^{E}\right) / h_{\text {exp }}^{E}\right]^{2}}{m}\right\} \ldots
\end{aligned}
$$

where $n_{\text {-and }} m$ are respectively the number of experimental $g^{E}$ and $h^{E}$ data points at a specified isothermal temperatures. $N$ is the number of isothermal system temperatures for the $g^{E}$ data and $M$ is that of the $h^{E}$ data. For minimizing the function $F$ a package program called MINUIT (James, 1978) was used. The MINUIT performs minimization and anal$y$ sis of the shape of a multiparameter function. It incorporates three different minimization techniques. These are the Fletcher, Monte Carlo and Simplex techniques. Each technique may be used alone or in combination with the others depending on the behaviour of the function and the requirements of the user. The MINUIT program also performs the non-linear error analysis and contour plotting that shows the confidence region. It does not require the analytical derivatives of the function, $F$, with respect to its free parameters.

\section{Results and Discussions}

Using data for $g^{E}$ and $h^{E}$, temperature dependent parameters of the modified UNIQUAC equation (Anderson and Prausnitz, 1978) were estimated for 24 binary systems. The MINUIT program used for this purpose is rather slow, which may also be due to search for a berter minimum after convergence. Estimated parameters, together with representation of $g^{E}$ and $h^{E}$ data and variance of the fit, are given in Table 1 . Some of the systems shown in the table have the experimental value of $h^{E}$ which is higher than the value that can be predicted by using the temperature independent parameters of the UNIQUAC equation. The average absolute error $S$ was calculated as

$$
\begin{aligned}
& S\left(g^{E}\right)=1 / n\left[\left|\Sigma\left(g_{\exp }^{E}-g_{\text {caic }}^{E}\right) / g_{\text {exp }}^{E}\right|\right] \ldots \ldots \ldots \\
& S\left(h^{E}\right)=1 / m\left[\left|\Sigma\left(h_{\exp }^{E}-h_{\text {calc }}^{E}\right) / h_{\text {exp }}^{E}\right|\right] \ldots \ldots
\end{aligned}
$$

The values of $S$ were calculated at each isotherm for $g^{E}$ and $h^{E}$ data. These indicate the performance of the UNIQUAC equation in representing $g^{E}$ and $h^{E}$ data simultaneously at various isotherms. The term $\sigma$ is the variance of the fit and is given by.

$$
\begin{aligned}
\sigma & =1 /\left(N^{N} n_{i}-N P\right)\left[\left(g_{\exp }^{E}-g_{\text {calc }}^{E}\right) / g_{\text {exp }}^{E}\right]^{2} \\
& +1 /\left(\stackrel{M}{\Sigma} m_{i}-N P\right)\left[\left(h_{\text {exp }}^{E}-h_{\text {calc }}^{E}\right) / h_{\text {exp }}^{E}\right]^{2} \ldots \ldots
\end{aligned}
$$

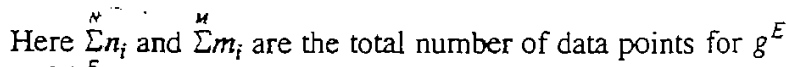
and $h^{E}$ respectively, while $N P$ is the number of parameters. 
TABLE 1

Simultaneous Representation of $g^{E}$ and $h^{E}$ Data by the UNIQUAC Equation Using the Temperature Dependent Parameters

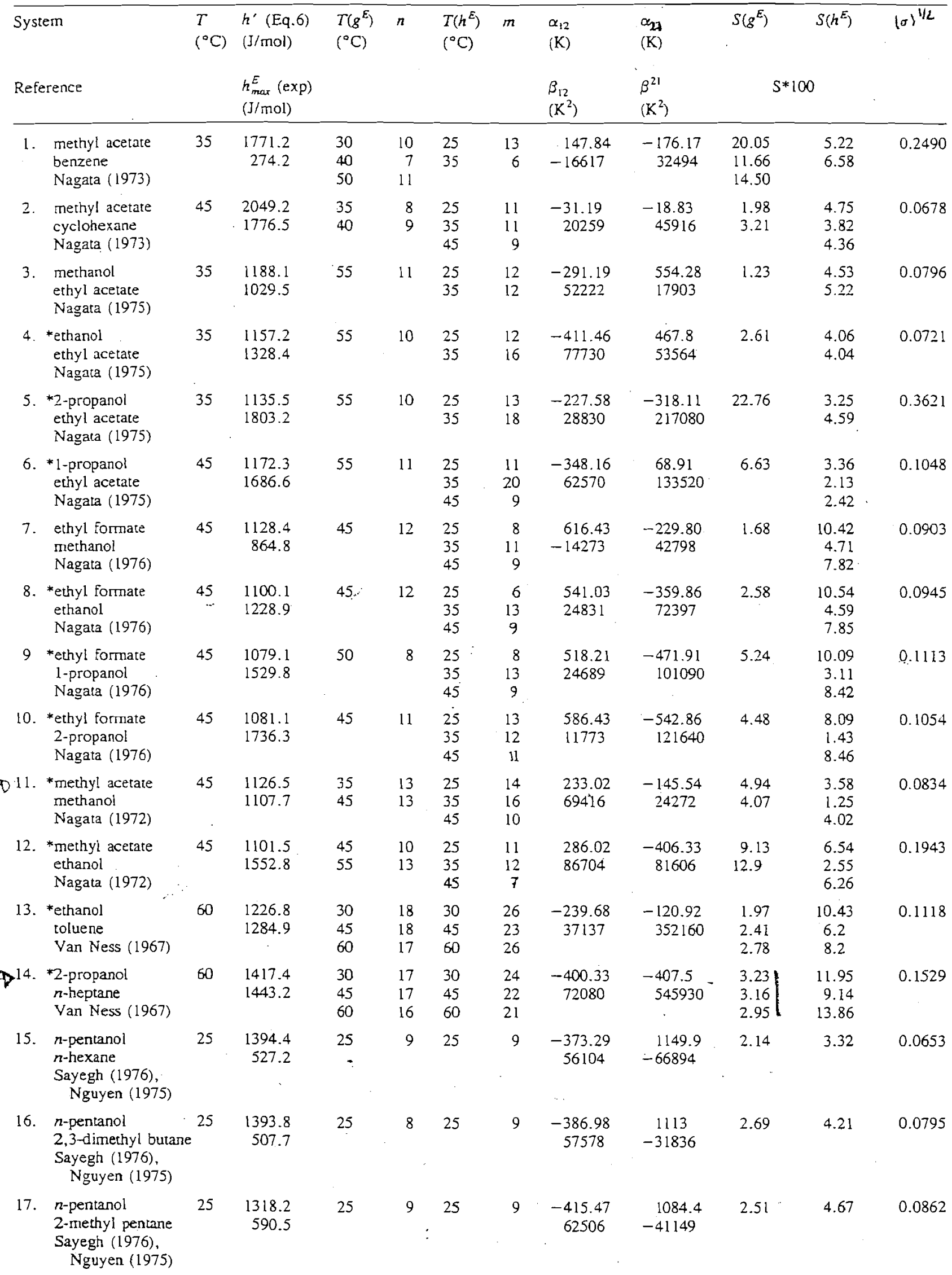

THE CANADLAN JOURNAL OF CHEMICAL ENGINEERING, VOLUME 67, JUNE, 1989 
TABLE I (continued)

Simultaneous Representation of $g^{E}$ and $h^{E}$ Data by the UNIQUAC Equation Using the Temperature Dependent Parameters

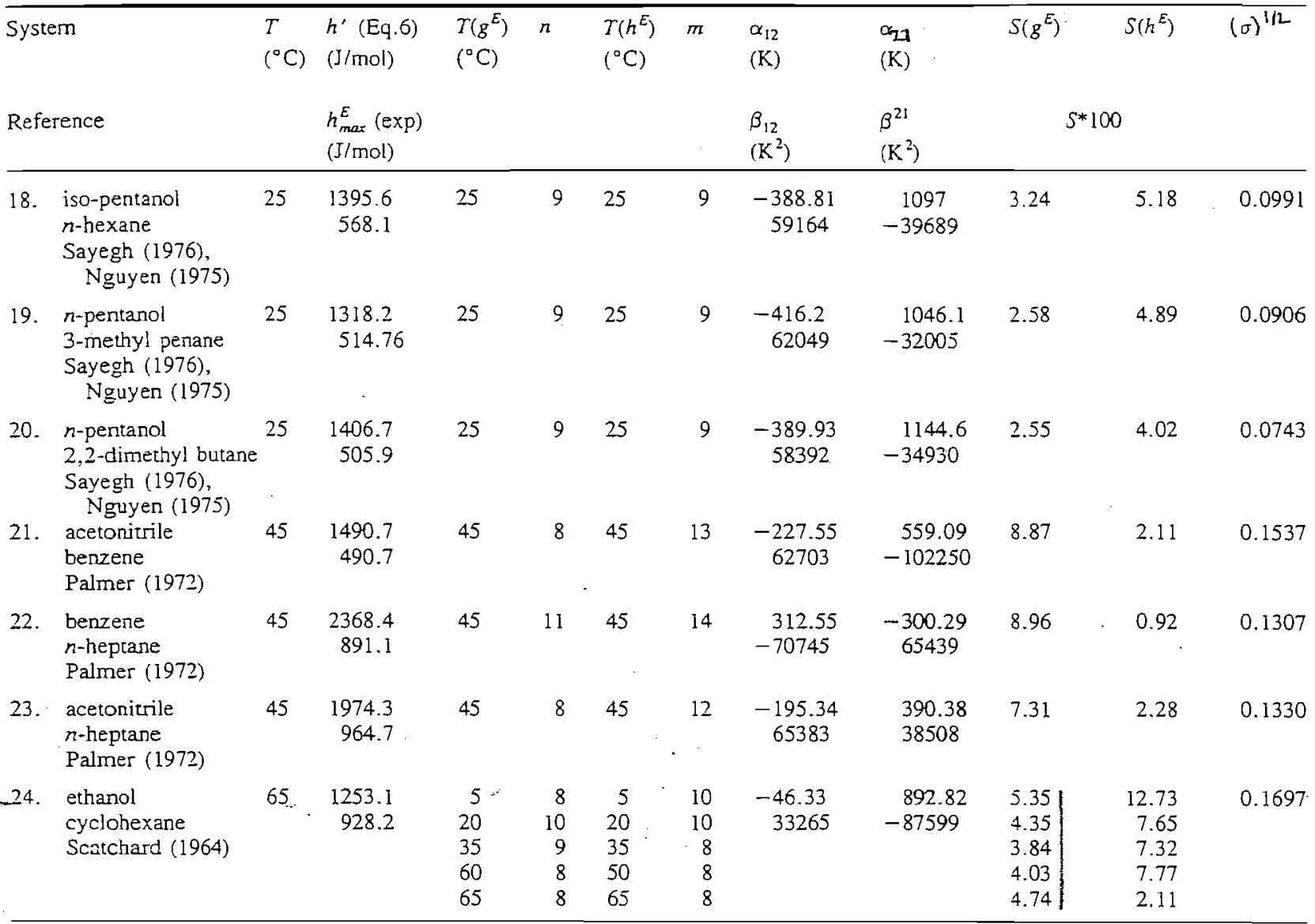

$n, m: \quad$ number of experinental $g^{E}$ and $h^{E}$ data points respectively, at a specified temperature

$S: \quad$ average absolute error

$\sigma: \quad$ variance of the fit

$\alpha_{i j}, \beta_{i j}$ : constants of the energy paraneter of the UNIQUAC equation $\left(a_{i j}=\alpha_{i j}+\beta_{i j} / T\right)$

*: the system for which the experimental value of $h^{E}$ is higher than that of the predicted value by the original UNIQUAC equation.

The estimated variance of the fit, $\sigma$, provides a measure of how well $g^{E}$ and $h^{E}$ data are represented simultaneously by the UNIQUAC equation. Except for some of the systems, such as methyl acetate-benzene and 2-propanol-ethyl acetate, the obtained values $S$ and $\sigma$ are satisfactory. The value of $S$ for either $g^{E}$ or $h^{E}$ is rather poor for these systems. The minimum and maximum values for $S\left(g^{E}\right)$ and $S\left(h^{E}\right)$ are $1.23-20.05$ and $0.92-13.86$ respectively, while they are 0.0678 and 0.249 for the variance of the fit. These indicate that Equation (7) provides also a reliable representation of temperature dependency of the energy parameters $a_{21}$ and $a_{12}$ for mixtures other than the ones containing alcohols. Table 1 also shows that the limitations on the UNIQUAC equation, for estimating $h^{E}$ data, can be overcome by treating the energy parameters as functions of temperature, as indicated by Equation (9).

The MINUIT program also performs the error analysis. The error matrix, also called the covariance matrix, is the inverse of the second derivative matrix of the function with respect to its free parameters. When the matrix is inverted, the diagonal elements of the inverse contain contributions from all the elements of the covariance matrix, where the correlations come from. Using the error matrix the offdiagonal elements of the correlation coefficient matrix is calculated as

$$
\mu_{i j}=c_{i j} /\left(c_{i j} \cdot c_{j j}\right)^{1 / 2} ; \mu_{i i}=1 ; \mu_{i j}=\mu_{j i} \ldots \ldots
$$

where $c_{i j}$ represents the elements of the error matrix. If $c$ is positive definite, $|\mu|<1$ for all elements. If $\mu=0$, then the parameters are uncorrelated and if $|\mu|=1$, the parameters are completely correlated. The global correlation coefficient is given by

$$
\mu_{k}^{2}=1-\left[c_{k k}\left(c^{-1}\right)_{k k}\right]^{-1}
$$

and is the correlation between it and that linear combination of the other parameters most highly correlated with it. All such coefficients should be between zero and one for a positive definite error matrix. The values of error matrix correlation coefficients and global correlation coefficients for some of the systems are given in Table 2 and 3 . As seen from the tables, the parameters for some of the systems are highly correlated. For such highly correlated parameters it is not possible to specify unique values from a given set of data. As discussed by Abrams and Prausnitz (1975) and Anderson and Prausnitz (1978), non-uniqueness is a common difficulty 
TABLE 2

Elements of Correlation Coefficient Matrix

$\left(\mu_{i i}=1 ; \mu_{i j}=\mu_{j i}\right)$

\begin{tabular}{lcccccc}
\hline System & $\mu_{21}$ & $\mu_{31}$ & $\mu_{32}$ & $\mu_{41}$ & $\mu_{42}$. & $\mu_{43}$ \\
\hline $\begin{array}{l}\text { ethanol } \\
\text { cyclohexane }\end{array}$ & -0.925 & -0.873 & 0.822 & 0.869 & -0.912 & -0.946 \\
$\begin{array}{l}\text { 2-propanol } \\
n \text {-heptane }\end{array}$ & -0.979 & 0.145 & -0.269 & -0.106 & 0.255 & -0.958 \\
$\begin{array}{l}\text { acetonitrile } \\
\text { benzene }\end{array}$ & -0.981 & -0.982 & 0.981 & 0.929 & -0.978 & -0.964 \\
$\begin{array}{l}\text { methyl acetate } \\
\text { cyclohexane }\end{array}$ & -0.988 & -0.994 & 0.977 & 0.990 & -0.994 & -0.991 \\
\hline
\end{tabular}

TABLE 3

Global Correlation Coefficients

\begin{tabular}{lccccc}
\hline & \multicolumn{5}{c}{$\mu_{k}^{2}$} \\
\cline { 2 - 5 } & $\alpha_{21}$ & $\beta_{21}$ & $\alpha_{12}$ & $\beta_{12}$ & $\sigma$ \\
\hline $\begin{array}{l}\text { System } \\
\begin{array}{l}\text { ethanol } \\
\text { cyclohexane }\end{array}\end{array}$ & 0.932 & 0.953 & 0.954 & 0.968 & 0.1697 \\
$\begin{array}{l}\text { 2-propanol } \\
n \text {-heptane }\end{array}$ & 0.985 & 0.985 & 0.936 & 0.953 & 0.1529 \\
$\begin{array}{l}\text { acetonitrile } \\
\text { benzene }\end{array}$ & 0.998 & 0.998 & 0.996 & 0.997 & 0.1537 \\
$\begin{array}{l}\text { methyl acetate } \\
\text { cyclohexane }\end{array}$ & 0.998 & 0.998 & 0.998 & 0.998 & 0.0678 \\
\hline
\end{tabular}

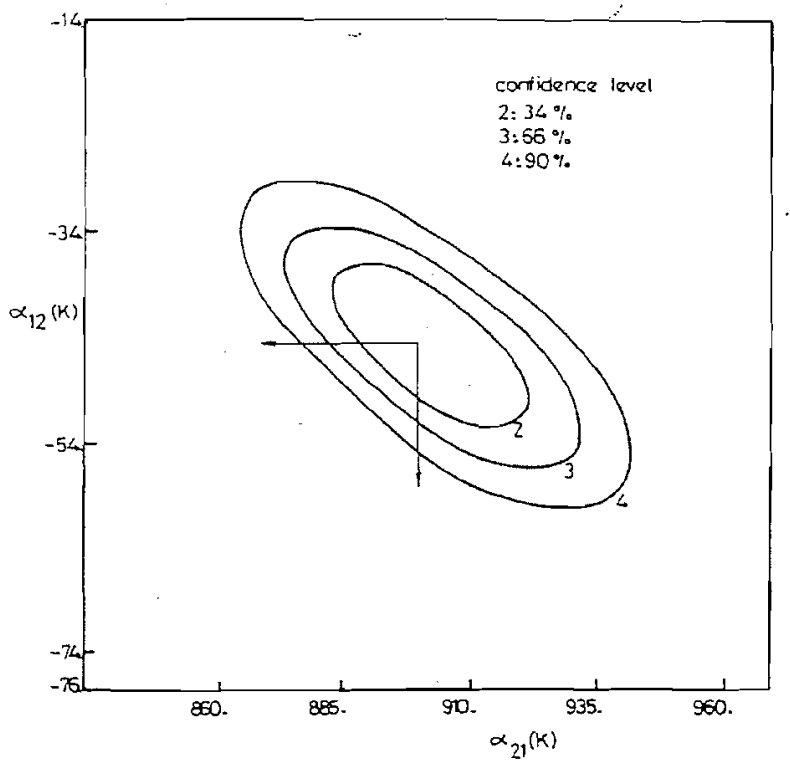

Figure 1 - Binary parameters, $\alpha_{12}$ and $\alpha_{21}$, and their approximate confidence regions for the ethanol-cyclohexane system.

for models that have only two parameters representing energy differences, as in the case for the UNIQUAC equation. Such problems have arisen when the same free energy function is used for two of the phases, as in liquid-liquid equilibria, at points where the mold fractions in two phases are identical.

Estimated confidence regions for some of the systems are shown in Figures 1-4. These are estimated from the eigenvalues and eigenvectors of the second derivative matrix. The

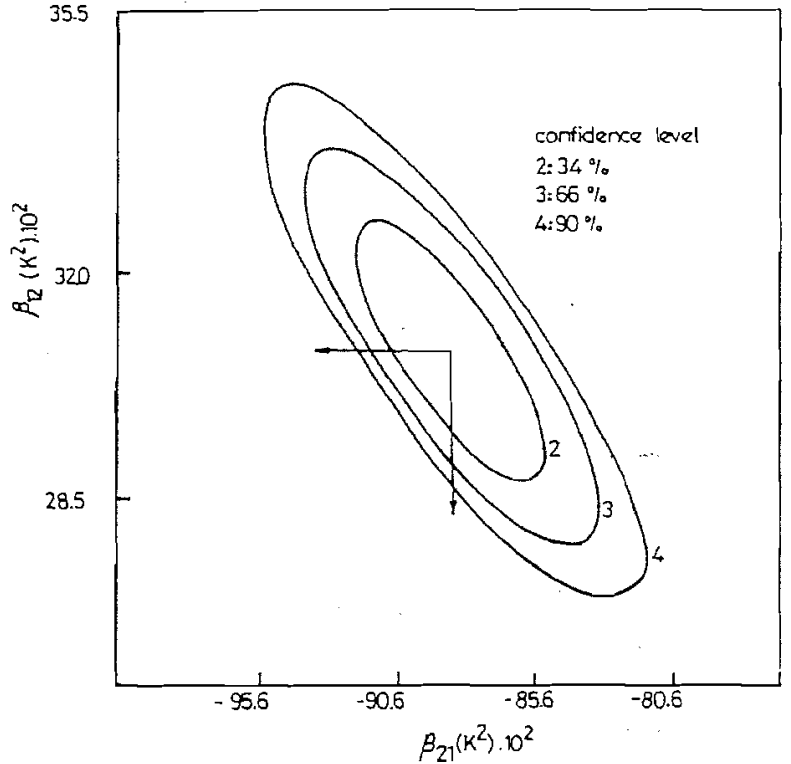

Figure $2-$ Binary parameters, $\beta_{12}$ and $\beta_{21}$, and their approximate confidence regions for the ethanol-cyclohexane system.

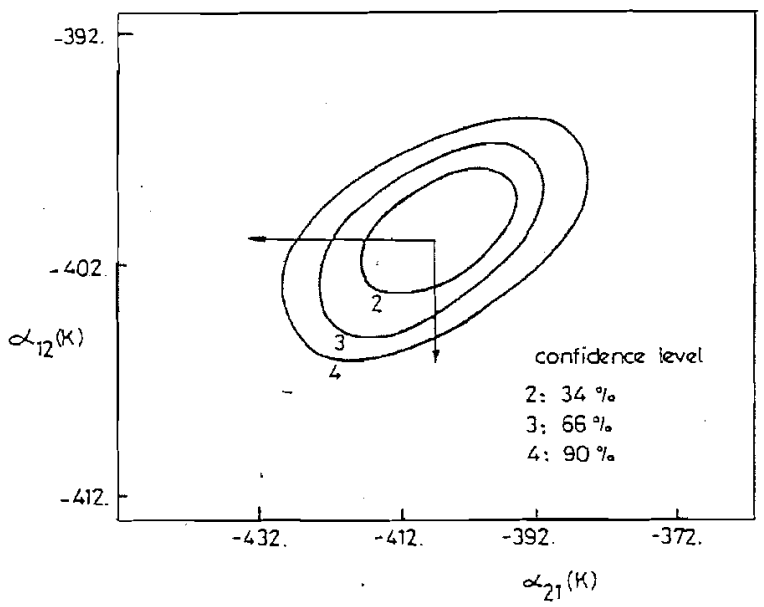

Figure 3 - UNIQUAC parameters, $\alpha_{12}$ and $\alpha_{21}$, and their approximate confidence regions for the 2-propanol-n-heptane system.

regions shown represent areas within which the parameter values can be expected to lie at a confidence level associated with the contours. The probability content of the confidence regions become very small as the number of parameters 


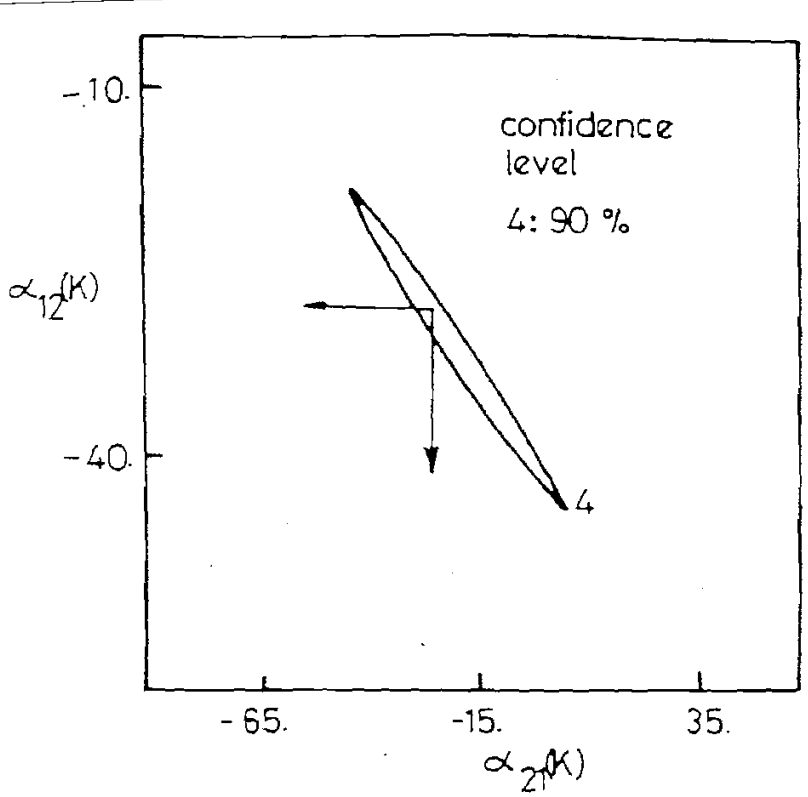

Figure 4 - UNIQUAC parameters, $\alpha_{12}$ and $\alpha_{21}$, and their approximate confidence region for the methyl acetate-cyclohexane system.

increases. The probability statement is the probability that all parameters take on values within the two standard deviation contour is $34 \%$, three standard deviation contour is $66 \%$ and four standard deviation contour is $90 \%$. In the Figures $1-4$ confidence regions for the systerns ethanolcyclohexane, 2-propanol-n-heptane, and methyl acetatecyclohexane are given. The figures show that the confidence regions become small and narrow as the estimated variance of the fit decreases. The confidence regions for the parameters $\beta_{21}$ and $\beta_{12}$ are large. This is seen in Figure 2 for the system ethanol-cyclohexane.

\section{Conclusions}

A simultaneous fit of excess Gibbs free energy and heat of mixing data for 24 binary systems are well made with the UNIQUAC equation whose parameters are assumed to be temperarure dependent. Treating the parameters as ternperature dependent, the UNIQUAC equation is able to represent larger values of $h^{E}$ data, and the effect of temperature on $h^{E}$ data and activity coefficient. This property is especially imporant in process calculations such as bubble point and distillation.

The MINUIT program performs satisfactorily in estimating the temperature dependent parameters. Since it does not need the partial derivatives of an objective function. with respect to parameters, it is easy to use. However the convergence is not rapid.

\section{Acknowledgernent}

The authors are grateful to the Computer Center of Cukurova Universiry for the computation facilities provided.

\section{Ciomenclature}

$$
\begin{aligned}
a_{i j}= & \text { UNIQUAC binary interaction parameter related to } \Delta u_{i j} \\
& \text { and } \tau_{i j}[\mathrm{~K}\} \\
c_{i j} \quad= & \text { elements of covariance matrix }
\end{aligned}
$$

$g^{\bar{E}}=$ excess molar Gibbs energy [ $\left.\mathrm{J} / \mathrm{mol}\right]$

$\mathscr{h}^{E}=$ excess enthalpy of mixing [J/mol]

$q_{i}^{\prime} \quad=$ molecular interaction area parameter for component

$P \quad=$ pressure $[\mathrm{Pa}]$

$R=$ gas constant $[\mathrm{J} / \mathrm{mol} \mathrm{K}]$

$T=$ absolute temperature $[\mathrm{K}]$

$S=$ average absolute error (Equations 11 and 12)

$\Delta u_{i j}=$ UNIQUAC binary interaction parameter [J/mol]

$x_{i}=$ liquid phase mole fraction of component $i$

\section{Greek letters}

$\alpha_{i j}=$ parameter of UNIQUAC equation related to $a_{i j}[\mathrm{~K}]$ (Equation 7)

$\beta_{i j}=$ parameter of UNIQUAC equation related to $a_{i j}[\mathrm{~K}]$ (Equation 7 )

$\gamma_{i}=$ activity coefficient for component $i$

$\hat{\theta}_{i} \quad=\quad=$ area fraction for component $i$ in residual contribution to the activity coefficient

$\mu_{i j}=$ elements of correlation coefficient matrix (Equation 14)

$\mu_{k}=$ elements of global correlation vector (Equation 15)

$\tau_{i j}=$ UNIQUAC binary parameter

$\sigma=$ variance of the fit (Equation 13)

\section{Subscripts}

$$
\begin{aligned}
\exp & =\text { experimental } \\
\text { calc } & =\text { calculated } \\
i, j & =\text { component } \\
\max & =\text { maximum }
\end{aligned}
$$

\section{References}

Abrams, D. S. and J. M. Prausnitz, "Statistical Thermodynamics of Liquid Mixtures: A New Expression for the Excess Gibbs Energy of Partly and Completely Miscible Systerns" Am. Inst. Chem. Eng. J. 21, 116-128 (1975).

Anderson, T. F. and J. M. Prausnitz, "Application of the UNIQUAC Equation to Calculation of Multicomponent Phase Equilibria 1. Vapour-Liquid Equilibria" Ind. Eng. Chem. Proc. Des. Dev. 17, 552-560 (1978).

Demirel, Y., "Comparison of New Moleculer Models in Fluid Phase Equilibria Predictions" Chim. Acta Turc. 10, 197-206 (1982)

Demirel, Y. and C. McDermott, "Prediction of Phase Behaviour and Bubble Point of Parially Miscible Systems", Chim. Acta Turc. 12, 173-188 (1984).

Fredenslund, Aa., J. Gmehling and P. Rasmussen. "Vapour-Iiquid Equilibria Using UNIFAC", Elsevier, Amsterdam (1977).

James, F., "Interpretation of the Errors on Parameters Given by MINUIT", Data Handlig Division CERN Geneva, Switzerland (1978).

Murthy, A. K. S. and D. Zudkevitch, "Effect of Heat of Mixing and Vapour-Liquid Equilibrium on Design. Performance and Economics of Distillation" Inst. Chem. Eng. Symp. Series 56, $1.1 / 51-1.1 / 78(1979)$.

Nagata, I., T. Ohta and T. Takahashi, "Excess Thermodynamic Functions of Methyl Acetate-Methanol and Methyl AcetateEthanol Systems", J. Chem. Eng. Data 5, 227-231 (1972).

Nagata, I., T. Ohta, M. Ogura and S. Yasuda, "Excess Gibbs Free Energies and Heats of Mixing for Binary Systems: Ethyl Formate With Methanol, Ethanol, 1-Propanol and 2-Propanol". J. Chem. Eng. Data 21, 310-313 (1976).

Nagata, I., T. Yamada and S. Nakagawa, "Excess Gibbs Free Energies and Heats of Mixing for Binary Systems Ethyl Actate With Methanol, Ethanol, 1-Propanol and 2-Propanol" J, Chem. Eng. Data 20, 271-275 (1975).

Nagata, I. and T. Yamada, "On the Parameters-Seeking Method of Local Composition Equations". J. Chem. Eng. Japan 3, $215-218(1978)$ 
Nagata. I., T. Ohca. T. Takahashi and K. Gotoh. "Thermodynamic Properties of Methyl Actate-Benzene and Methyl AcetateCyclohexane Mixtures". J. Chem. Eng. Japan 6, 129-133 (1973).

Nguyen, T. H. and G. A. Ratcliff, "Heats of Mixing of Binary Systems of Iso Pentanol and $n$-Pentanol With Hexane Isomers at $25 \mathrm{C}$ : Mejsurement and Prediction by Analycical Group Solution Models". J. Chem. Eng. Data 20, 256-258 (1975).

Novak. J. P., P. Vanka. J. Suska, J. Marous and J. Pick, " Applicability of the Three-Constant Wilson Equation to Correlation of Strongly Nonideal Systems", Coll. Czech. Comm. 39, 3593-3598 (1974).

Paimer. D. A. and B. D. Smith, WThermodynamic Exeess Property Measurements for Acetonitrile-Benzere-n-Heptane System at 45 C'. J. Chem. Eng. Data 17, 71-76 (1972).

Reid, R. C., J. M. Prausnitz and T. K. Sherwood, "The Properries of Gases and Liquids", McGraw-Hill New York (1977).

Renon. H.. L. Asselineau. G. Cohen and C. Raimbault, "Calcul sur Ordinateur des Équilibres Liquide-Vapour et LiquideLiquide" Editions Techniq, Paris (1971).
Sayegh, S. G. and G. A. Ratcliff, "Excess Gibbs Energies of Binary Systems of isopentanol and n-Pentanol With Hexane Isomers at $25 \mathrm{C}$ : Measurement and Prediction by Analytical Group Solution Model". J. Chem. Eng. Data 21, 71-74 (1976).

Scatchard, G. and F. G. Satkiewitcz, "Vapour-Liquid Equilibrium XII. The System Elhanol-Cyclohexane From 5 to $65^{\prime \prime}$, J. Am. Chem. Soc. 86, 130-133 (1964).

Van Ness, H. C., C. A. Soczek, G. L. Peloguin and R. L. Machado, "Thermodynamic Excess Properties of Three Alcohol-Hydrocarbon System" . J. Chem. Eng. Data 12, 217-224 (1967).

Wilkinson, S., "The Predicrion of Vapour-Liquid Equilibria From Heat of Mixing Data", Inst. Chem. Eng. Symp. Series 56. $1.1 / 1-1.1 / 16$ (1979).

Manuseript received March 10, 1988; revised manuscript received July 28. 1988; accepted for publication August 23, 1988 . 